\title{
Understanding processes for model-based enterprise transformation planning
}

\section{Stephan Aier* and Jan Saat}

\author{
Institute of Information Management, \\ University of St. Gallen, \\ Mueller-Friedberg-Strasse 8, \\ St. Gallen 9000, Switzerland \\ Fax: +41-71-224-21 89 \\ E-mail: stephan.aier@unisg.ch \\ E-mail: jan.saat@unisg.ch \\ ${ }^{*}$ Corresponding author
}

\begin{abstract}
The aim of this paper is to deliver insight into enterprise transformation planning incorporating Enterprise Architecture (EA) models. The paper is based on analytically developed approaches to model-based enterprise transformation planning and uses six case studies to evaluate and extend the existing planning processes. To understand the planning situations and their respective planning processes, we cluster the observed processes and link them to empirically derived EA realisation forms. Thus, the resulting process model induced from our empirical observations can be tailored to fit specific needs of an organisation depending on its realisation form of EA.
\end{abstract}

Keywords: EA; enterprise architecture; enterprise transformation; EM; enterprise modelling; case study; empirical analysis.

Reference to this paper should be made as follows: Aier, S. and Saat, J. (2011) 'Understanding processes for model-based enterprise transformation planning', Int. J. Internet and Enterprise Management, Vol. 7, No. 1, pp.84-103.

Biographical notes: Stephan Aier is a Research Project Manager at the Institute of Information Management at the University of St. Gallen, Chair of Professor R. Winter. He studied Industrial Engineering and Management at the Berlin University of Technology, Germany, where he received his $\mathrm{PhD}$ in 2006. He is a founding member of the competence centres Enterprise Application Integration (2002) and Enterprise Architecture (2005) at the Berlin University of Technology. Since 2006, he has headed the Research Group Integration and Architecture at the Institute of Information Management. He is one of the Editors of the Enterprise Architecture book series and co-organiser of the 2008 and 2009 Trends in Enterprise Architecture Research (TEAR) workshops.

Jan Saat is a Research Assistant and PhD student at the Institute of Information Management at the University of St. Gallen, Chair of Professor R. Winter. He holds a Master's Degree in Business Administration from the TU Freiberg, Germany. His focus of research and industry project activities is on enterprise architecture management and service-oriented architectures. 


\section{Introduction}

Enterprise Modelling (EM) addresses the modelling of business processes, goals, strategy, information entities, business structure, support systems and personnel of an enterprise (Katz, 1990; Fox and Gruninger, 1998). Enterprise models integrate models of information systems and models of supported business functions and can provide the transparency required for systematic support of enterprise transformation from 'business to IT' (Dietz, 2006; Hoogervorst, 2009). By representing both organisational and technical infrastructure, EM may also provide a broad and comprehensive view of an entire corporation or government agency (Kirikova, 2000), referred to as Enterprise Architecture (EA) (Lankhorst, 2005; Jonkers et al., 2006; Tyler and Cathcart, 2006; Winter and Fischer, 2007; Rohloff, 2008).

To provide efficient support for transformation, EA has to be driven by business or IT-oriented application scenarios (Winter et al., 2007) based on stakeholders concerns (Ylimäki, 2006; Niemi, 2007; Op't Land et al., 2009) ensuring a high degree of goal orientation (Lankhorst, 2005; Rohloff, 2008). Since the involvement of heterogeneous stakeholder groups such as application owners or business developers may create conflicting requirements in a complex environment, an appropriate documentation and communication of the enterprise models are vital (Liles and Presley, 1996). A suitable degree of formalisation is needed to ensure traceable and repeatable results in an environment characterised by the division of labour (Shaw, 1990; Vernadat, 1996).

While documentation and analysis of EA models (represented by as-is models) are well covered in academic and practitioner approaches (Zachman, 1987; Kosanke et al., 1999; Wegmann, 2002; Bernus et al., 2003; Jonkers et al., 2004; Theuerkorn, 2004; Lankhorst, 2005; Johnson and Ekstedt, 2007; Winter and Fischer, 2007), EM for planning transformation purposes is covered rarely so far. Since neither the corporation or government agency itself, nor their environments remain static in the course of a transformation project, and because to-be models may change as projects are launched, the consideration of dynamic aspects is important for planning a transformation programme. Well-structured methods for EA planning are needed to enable division of labour and a common understanding among the stakeholder groups in the planning process (Frank, 2002; Jonkers et al., 2004).

A method may be defined as a systematic aid that guides the transformation of a work system (Alter, 2003, 2006) from an initial state to a target state (Bucher et al., 2007). Core components of a method are design activities structured in a process model, techniques, an information model and a role model aiming at creating a specific design result (Gutzwiller, 1994; Brinkkemper, 1996) - which in our case is a set of to-be EA models and respective transformation plans.

However, it is the very nature of EA that the EA itself, the questions addressed by EA, the stakeholders concerned with EA, the planning of EA, and methods for planning, transforming or using EA, cover a broad range (Schelp and Winter, 2009; Schönherr, 2009). It is therefore unlikely that there is a 'one-size-fits-all' EA planning method. Depending on the parameter values of a variety of context factors, different methods - or at least different configurations or adaptations of a method - are needed. Such approaches are discussed in situational method engineering (Kumar and Welke, 1992; Harmsen et al., 1994; van Slooten and Hodes, 1996; Bucher et al., 2007). 
This contribution focuses on the enterprise transformation planning process and aims at understanding different ways EA is implemented in different situations as well as their implications for an enterprise transformation planning process model.

On the basis of an analytically derived EA planning process model, we have analysed six case studies to comprehend the differences and similarities backed up by previous work on the classification of EA realisation approaches (Aier et al., 2008; Riege and Aier, 2009).

This paper aims at answering the following research questions:

1 What are the differences between EA planning processes derived analytically by scientists and planning processes employed by practitioners?

2 What are the differences and similarities among EA planning processes observed in practice?

3 How do different planning processes observed in practice relate to different EA realisation approaches?

To answer these questions, we analyse six case studies and compare the results with analytically derived results from previous work. To better understand the peculiarities of these cases, we link them to EA realisation approaches observed in practice.

The remainder of this paper is structured as follows. Section 2 reviews related work in the field of EA planning. Section 3 elaborates on the employed research model providing relevant contingency factors to classify EA realisation approaches as well as clusters of EA realisation approaches actually observed. In Section 4, we present the essence of six case studies on EA planning processes. Section 5 presents the results of our analysis linking the cases to the existing EA realisation approaches. The paper closes with a discussion of results in Section 6 and a conclusion in Section 7.

\section{Related work}

The term 'EA planning' was first introduced by Spewak who defines EA planning as "the process of defining architectures for the use of information in support of the business and the plan for implementing those architectures" (Spewak and Hill, 1993). The underlying understanding of EA covers the whole of data, applications and technology. Plan - in this context - is referred to as the definition of the blueprint for data, applications and technology as well as the process of implementing the blueprint within an organisation. The work of Spewak was updated in 2006 emphasising the importance of business knowledge and organisational issues during the planning process (Spewak and Tiemann, 2006). On the basis of the current state of the architecture, the to-be architectures for data, application and technology are defined using business knowledge, which determines major requirements. Yet, the process ignores that the business requirements and therefore respective to-be architectures can change while the process is being executed.

On the basis of an extensive literature review, Pulkkinen and Hirvonen (2005) and Pulkkinen (2006) propose an EA development process model that guides the incremental planning and development of EA. Because of the high complexity of EA development, only discrete EA development projects are considered. Moreover, the EA process model is intended to cover both EA planning and enterprise systems development. 
The authors emphasise the aspect of user participation and decision-making in the process, which is structured by the EA management grid (Hirvonen and Pulkkinen, 2004). Following this two-dimensional grid, the process model proposes that even at enterprise level technology decisions should be made and then transferred to the underlying levels.

The EA process is further refined in Pulkkinen (2006), which is depicted in Figure 1: Pulkkinen proposes parallel domain-level decisions implementing the decisions made on the enterprise level (arrow A). After parallel sub-cycles in domain decisions, system-level decisions are derived (arrow C). Additionally, the reuse of successful implementations from lower levels to the enterprise level is supported (arrow B). The author points out the importance of detecting domains within EA development, which may result in concurrent planning efforts requiring additional coordination.

Figure 1 The refined EA process

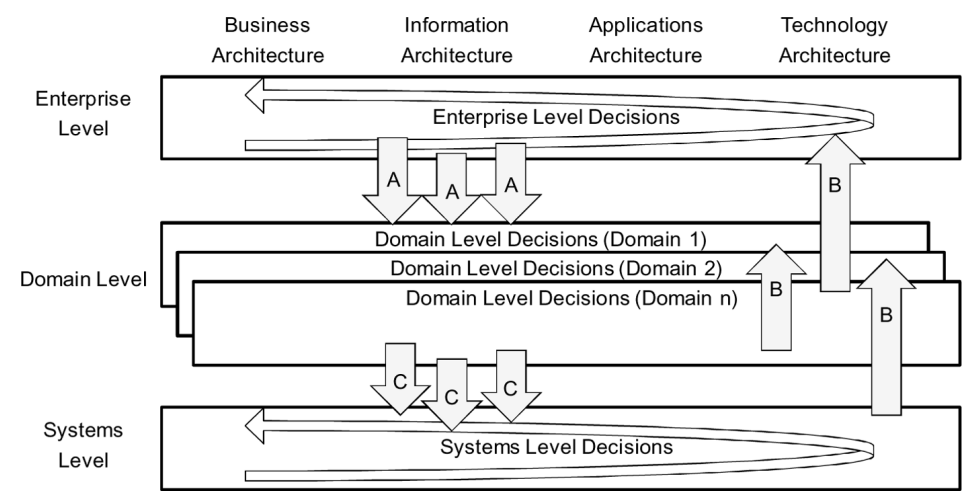

Source: Pulkkinen (2006)

Similar approaches to establish the EA, comprising evaluation, creation and development, are presented by Op't Land et al. (2009) and Niemann (2006).

Leppänen et al. (2007) propose a first step towards an EA planning method by developing a contingency framework that lists several situational factors derived from method engineering and information system development literature. These factors include enterprise/organisational characteristics, persons involved, goals pursued and characteristics of the EA method to be constructed.

In its core, the Open Group Architecture Framework (TOGAF) defines the Architecture Development Method (ADM) (The Open Group, 2009). However, even though TOGAF version 9 has improved in this aspect when compared with version 8.1 , TOGAF focuses very much on IT architecture and covers business architecture superficially only. Moreover, TOGAF does not address dynamic aspects of EA planning but is based on a strict plan-build-run cycle.

In summary, related work in the field of EA planning focuses on IT landscapes and does not comply with our broad understanding of EA. Particularly existing approaches do hardly address dynamic aspects of EA planning like plan deviations, different dimensions of time (like modelling time and the time models are valid) or multistage planning processes.

Only recently the works of Buckl et al. (2009a, 2009b), as well as contributions from the CIAO! Community (Albani et al., 2009) (e.g., Sousa et al. (2009) and Aier et al. 
(2009)) address a comprehensive modelling method for planning purposes in the EA context. While Buckl et al. (2009a) propose a set of metamodel requirements for modelling temporal aspects, their proposal focuses on application landscapes. However, they take into account important temporal dimensions, e.g., the time a model is created and the time a model should be valid for the past, the present and the future, as well as different variants of future models (Buckl et al., 2009a). Recommendations or a framework addressing the transformation process itself cannot be found in these approaches though.

Sousa et al. (2009) take the dynamic evolution of enterprise models into account, providing a formal approach to generate blueprints of EA from the existing project management sources. By applying this bottom-up approach, the current and the planned state of the EA as well as its evolution can be visualised. In doing so, this approach reconstructs EA models from the existing project plans rather than considering the derivation of projects from model information.

Aier et al. (2009) have addressed the issues of dynamics analytically by defining complexity levels to represent dynamics in EA planning. On the highest of the seven complexity levels, a comprehensive planning and transformation approach has to comply with the following requirements:

- model as-is state

- model to-be states

- model transformation paths from as-is to to-be states

- model alternatives for models and paths for a respective point in time

- model an unlimited number of points in time as well as the respective transformation paths

- model deviations from plans.

These requirements create an environment in which transformation from as-is to to-be states can be planned. On the basis of these requirements, Aier et al. define an EA planning process capable to fulfil these requirements (Figure 2).

Figure 2 EA planning process

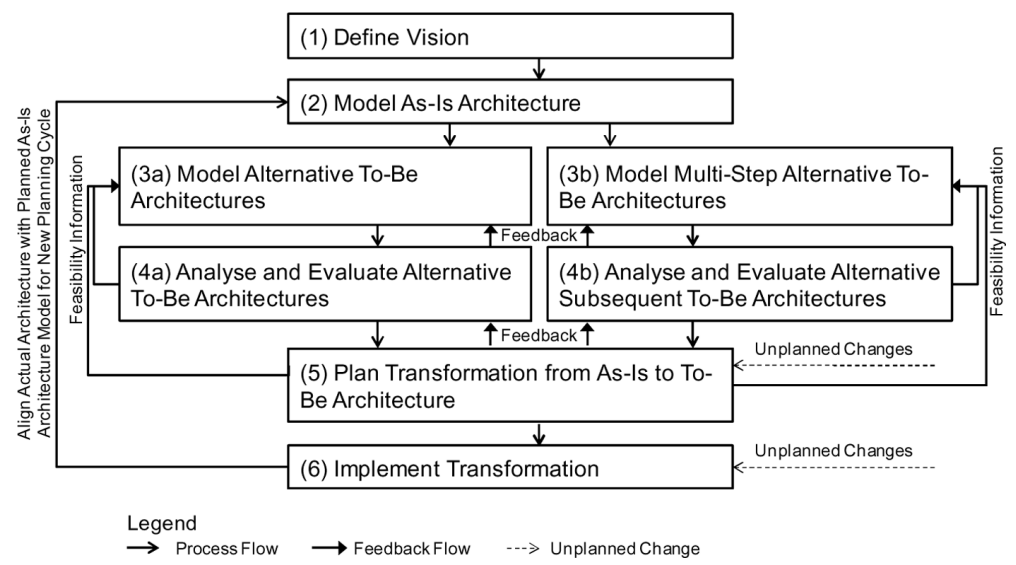

Source: Aier et al. (2009) 
However, Aier et al. do neither contrast their planning process with empirical findings nor elaborate on the different forms of EA implementation influencing the EA planning process. Therefore, we use the EA planning process proposed by Aier et al. as a baseline and reflect their model with case study observations.

\section{Research framework}

The aim of this contribution is to understand the differences of EA planning approaches for different implementations of EA management. Therefore, it is necessary to have a conceptualisation of EA management that is suitable to compare different EA management cases by using relevant parameters. Our literature analysis resulted in very few contributions dealing with the identification of contingency factors and related situations of EA management in practice.

One of the first contributions by Leppänen et al. (2007) empirically derived a contingency framework for EA method engineering. While they describe relevant contingency factors as well as their relations, they do not identify actual occurrences of their factors in the field.

Winter et al. (2007) empirically analysed EA approaches by analysing their underlying application scenarios. On the basis of this analysis, Aier et al. (2008) as well as Riege and Aier (2009) conducted a broader empirical analysis to identify relevant factors to derive a classification of EA realisation approaches as well as to describe and classify observed approaches. As a result, three contingency factors were identified.

In this paper, we therefore build upon the results of Aier et al. to describe actual EA realisation approaches and link them to the observed EA planning approaches. In the remainder of this section, we shortly describe the contingency factors as well as the resulting situations of EA management developed by Aier et al.

Factor 1 - Adoption of advanced architectural design paradigms and modelling capabilities: The items of contingency factor 1 describe successful ways to adopt the concept of EA. On the one hand, it involves well-established architecture design paradigms, which emphasise the layered structure of EA. The findings denote that developing EA needs a certain degree of decoupling between the different EA layers as indicated by the principles of service orientation and thus foster reuse of EA artefacts (Aier and Winter, 2009). On the other hand, factor 1 points out that a further enhancement of EA also depends on the dimension of the EA documentation. To allow for continuous development, not only loosely coupled artefacts, but also an idea of how to approach a future development stage is decisive. EA then contributes to business/IT alignment (Luftman, 2000) by offering simulation capabilities, which presupposes different variants of its to-be structures.

Factor 2 - Deployment and monitoring of EA data and services: Factor 2 describes the deployment of EA within the organisation. It is required to establish a consistent monitoring of EA data and services to further enforce the deployment. This can be assisted by the role of an EA quality manager who is responsible for observing periodic reviews of EA data and EA processes (Fischer et al., 2007). A high degree of EA deployment puts the organisation in the position not only to reduce its costs for maintenance activities, software and hardware licences, but also to ensure that similar 
concerns are treated equally and according to the parameters of the EA roadmap. Sophisticated EA analysis techniques are applied.

Factor 3 - Organisational penetration of EA: The third contingency factor accounts for the penetration of EA in the organisation. The findings suggest that the overall level of penetration is influenced by the degree of EA results and EA models are used by a broad range of stakeholders. According to this analysis, EA is a suitable tool not only to support IT-related work, but also to serve the business units and to provide reliable information to management units (Kurpjuweit and Winter, 2009). The findings suggest that as the level of organisational penetration increases with the organisation's capability to clearly communicate EA benefits to the potential stakeholders. Therefore, the third factor describes the way EA is perceived and utilised across the organisation. A high level of organisational penetration leads to higher acceptance, and less misinterpretation of EA within the organisation, respectively.

To illustrate how EA is actually realised, Aier et al. partitioned their data set into different subsets by means of a hierarchical cluster analysis. The factor values of the three contingency factors were used as input data. Applying the cluster analysis, three clusters to represent three different EA approaches were identified (Figure 3).

Figure 3 EA realisation approaches (see online version for colours)

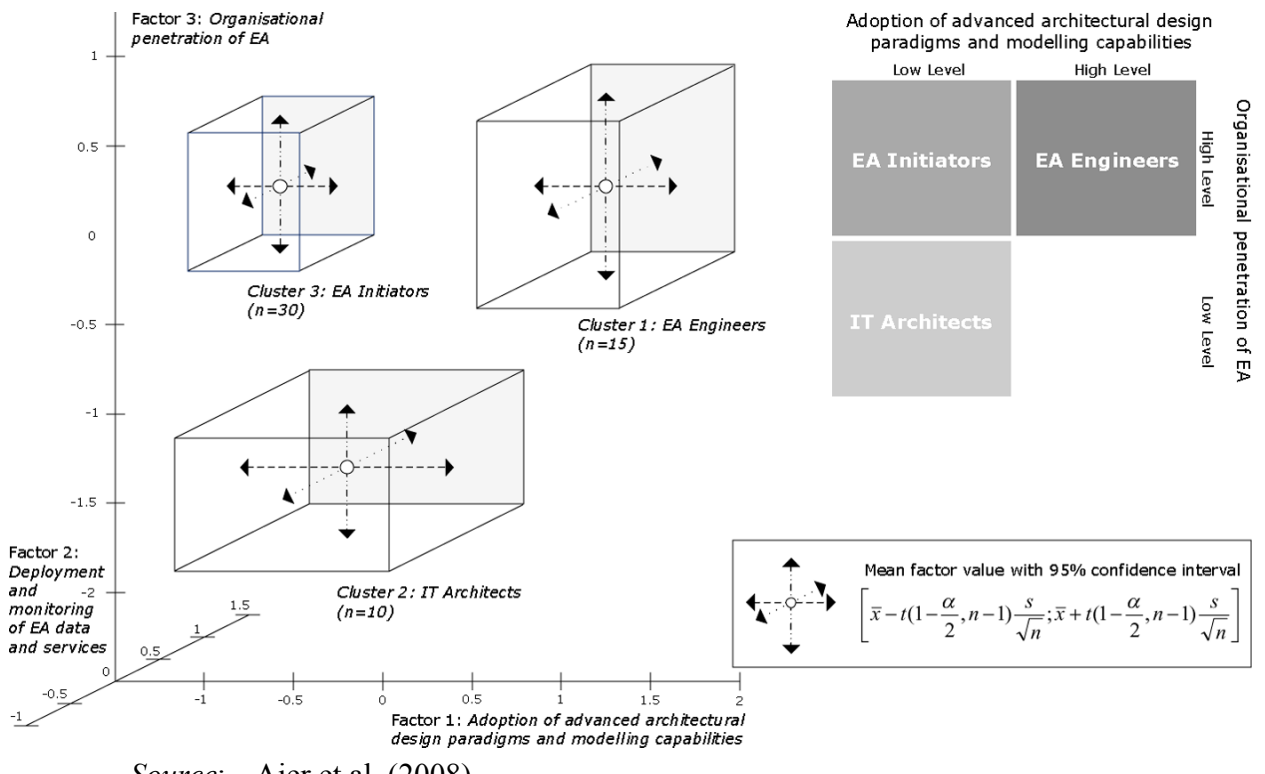

Source: Aier et al. (2008)

Figure 3 also illustrates the corresponding two-dimensional classification matrix, which excludes factor 2 as it does not account for significant cluster distinction. The matrix illustrates the distinct EA realisation approaches considering factors 1 and 3. For both dimensions, high and low levels are distinguished, which refer to either high or low parameter values. Aier et al. interpreted the clusters and metaphorically described the respective organisations as EA Engineers, IT Architects and EA Initiators. While these clusters do describe neither EA maturity levels nor any sequence or continuum, they reflect distinct EA realisation approaches rooted in their individual parameter values of 
the respective contingency factors. To understand the assignment of our case studies to these realisation approaches, we outline the three clusters briefly:

EA Engineers: All organisations assigned to this cluster are characterised by sophisticated implementation of architectural design paradigms. They understand EA as an instrument not only to represent a current structure of the organisation, but also to deliver a roadmap for a future structure. It is reasonable to assume that organisational penetration is rather advanced. They are using EA rather as an IT instrument, but also as a means of communication with the business. The organisations of this cluster understand EA as a valuable instrument to develop and thus transform EA as a whole. They can also rely on a progressive perception of EA within the business and management units. EA engineers in its current state have an intermediate maturity regarding the employment and monitoring of EA data and services (factor 2).

IT Architects: The second cluster is made up of organisations with a low level of both the organisational penetration of EA and the adoption of advanced architectural design paradigms and modelling capabilities. This combination can be characterised as an observant attitude regarding a holistic EA. In this case, EA focuses primarily on IT architecture and, therefore, EA data is basically used in traditional IT project development. The relatively high value regarding the second factor supports this characteristic as it indicates a high deployment of (IT-related) EA data. The organisations of the second cluster are well anchored in the IT domain. However, this limited architectural understanding is an obstacle to really leverage the value of available IT understanding, models and methods. Rather advanced architectural design paradigms e.g., service orientation - are not much developed in this cluster because they require a certain amount of organisational penetration.

EA Initiators: These organisations are characterised by a high level of organisational penetration of EA. It is, therefore, reasonable to assume that the potential benefits of EA are recognised among these organisations. EA is understood not only as IT architecture, but also as an instrument to foster the alignment of IT and business. However, EA primarily focuses on documentation. EA initiators put emphasis on transparency as the necessary precondition to realise benefits from EA application. They are particularly interested in implementing relevant applications to demonstrate these benefits. This also explains the need for more sophisticated analysis techniques, which EA initiators lack.

\section{An explorative study on EA planning processes}

\subsection{Interview design}

To gain insight into EA planning processes, an empirical study with six European companies was conducted. The research approach of this study follows commonly accepted case study methods. A case study is an empirical enquiry, performed for example by interviews, surveys or observations that investigate a contemporary phenomenon within its real-life context, especially when the boundaries between phenomenon and context are not clearly evident (Yin, 2003). Particularly in this case, where different approaches to planning processes are subject to analysis, a variety of context factors have to be taken into account. Data was collected in face-to-face interview 
sessions with chief architects and CIOs of six different companies. The companies chosen for this study have a long-term experience with EA and have architecture management structures in place. The selection of participants ensures a cross-industry view, considering diverse maturity levels within EA planning. The maturity range covers companies that use EA for the high-level documentation of their structures and have implicit processes for road mapping and EA planning, while others refer to well-defined EA planning processes with dedicated governance in place. With two companies, individual research projects on EA management have been done. These projects provided the opportunity to contact a broad range of employees and roles to gain additional insight into internal changes in structure, state and strategy of both IS and business perspectives.

The interview guidelines were designed based on thorough research of contemporary practices in EA planning cases and reviewed by experts from the scientific community and industry partners beforehand. The interview design itself is aimed at the collection of qualitative data by using open questions, which seems appropriate considering the variety of maturity levels of EA planning found in corporations or government agencies so far.

\subsection{Essence of case studies}

Because of participant's request, the case studies have been made anonymous to prevent drawbacks on individual situations.

Case study 1 - European Railway Company: The company has been using EA intensively for four years. After having documented the applications inventory comprising 1200 items, business processes and used technologies were also modelled. The EA planning process is thoroughly specified using conventions and guidelines. Change requests are derived from the business strategy or business requirements. To-be models are designed accordingly and used to support cost and feasibility estimation. Finally, the project portfolio is updated and operational transition planned.

Case study 2 - Swiss Telecommunications Provider: EA has been an important instrument of documentation and planning for several years. Core business challenge of the company is the enormous pace of innovations and products in the telecommunications sector. Therefore, business and IT are closely interconnected in products and service design. A pragmatic tool is used for parts of the documentation. Core challenge in EA planning is the management of project portfolios. As different units may prioritise different projects, a centralised governance board is responsible to decide upon budgets to assure the best alternative for the entire company. The EA planning process is well defined and involved roles and documents are specified to support fast decision-making and change implementation.

Case study 3-German Automotive Manufacturer: The company has been using EA for two-and-a-half years while the launch of first projects in Service-Oriented Architectures (SOAs) was the main driver to establish an EA organisation and specify respective roles and processes. A commercial EA tool was used from the start. As the company is globally active, the degree of utilisation in documentation, analysis and planning varies among the units and countries. So far, EA planning is primarily an issue in applications and technology planning. The results are consolidated and evaluated by an architecture board before implementation projects are launched. Projects are monitored using quality gates. 
Case study 4 - European Railway Company: The public transport industry as a whole and the company under consideration are very infrastructure-driven and characterised to engage in long-term planning. The company has been utilising EA models for 10 years, uses an EA tool and several modelling and governance standards. The process for EA planning is implicitly defined within EA governance. Besides the development of to-be models, project coordination and monitoring are important use cases in EA planning.

Case study 5 - Swiss IT Outsourcing Provider: As an IT outsourcing provider for the financial services industry, the company's purpose is the development, maintenance and operation of a banking platform for their customers. This platform is currently being rebuilt from a host environment to a three-tier client server architecture (SOA). Management and harmonisation of the complex transformation projects in this context are core use cases of EA planning. The planning process results in to-be models, roadmaps, and milestone definitions for the transition.

Case study 6 - Swiss Energy Company: The company faces the upcoming liberalisation of the Swiss utility market. As the industry is very information driven, close interaction of business and IT units is regarded as an essential success factor. The company uses a pragmatic planning approach to design application landscapes on a domain level. Redundancy detection, prioritisation of courses of action, and project portfolio management is conducted on enterprise level. Variants for to-be models are evaluated using business case calculations and check for architectural conformity.

\subsection{Planning processes}

As EA planning is approached in different ways by the companies within the conducted case studies, the findings were normalised and terminology unified to achieve comparability. The activities identified within the planning processes are depicted in Table 1.

Table 1 Activities in EA planning case studies

\begin{tabular}{|c|c|c|c|c|c|c|c|c|c|c|}
\hline \multicolumn{11}{|c|}{ Activities in EA planning } \\
\hline & 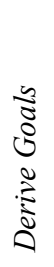 & 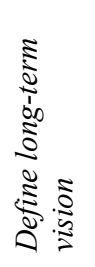 & 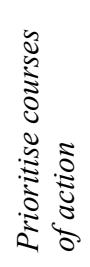 & 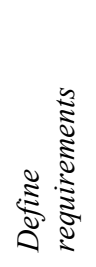 & 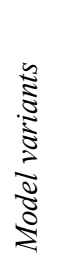 & 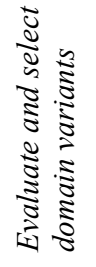 & 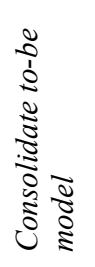 & 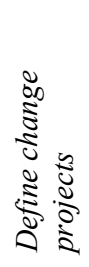 & 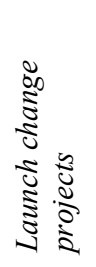 & 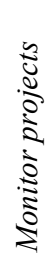 \\
\hline Case study 1 & $\mathrm{X}$ & $\mathrm{X}$ & & $\mathrm{X}$ & & & $\mathrm{X}$ & $\mathrm{X}$ & $\mathrm{X}$ & $\mathrm{X}$ \\
\hline Case study 2 & $\mathrm{X}$ & $\mathrm{X}$ & $\mathrm{X}$ & $\mathrm{X}$ & $\mathrm{X}$ & $\mathrm{X}$ & $\mathrm{X}$ & $\mathrm{X}$ & $\mathrm{X}$ & $\mathrm{X}$ \\
\hline Case study 3 & & $\mathrm{X}$ & & $\mathrm{X}$ & & & & $\mathrm{X}$ & $\mathrm{X}$ & \\
\hline Case study 4 & $\mathrm{X}$ & $\mathrm{X}$ & & $\mathrm{X}$ & & & & $\mathrm{X}$ & $\mathrm{X}$ & $\mathrm{X}$ \\
\hline Case study 5 & & $\mathrm{X}$ & $\mathrm{X}$ & $\mathrm{X}$ & $\mathrm{X}$ & $\mathrm{X}$ & $\mathrm{X}$ & $\mathrm{X}$ & $\mathrm{X}$ & $\mathrm{X}$ \\
\hline Case study 6 & & $\mathrm{X}$ & & $\mathrm{X}$ & $\mathrm{X}$ & $\mathrm{X}$ & & $\mathrm{X}$ & $\mathrm{X}$ & \\
\hline
\end{tabular}


The structural comparison gives first insights to similarities and differences of the EA planning processes observed in practice (cf. research question 2). Common activities among the entire sample are the definition of vision and requirements, as well as definition and launch of change projects. Rare activities include the prioritisation of courses of action, modelling and evaluation of variants.

The resulting approaches to EA planning are condensed to one extensive planning process covering three major phases, namely strategic planning, operational planning and implementation. Strategic EA planning bridges EA planning to the strategy process of the entire corporation by deriving goals for EA development from the overall strategy and deriving a long-term vision for architectural development. The vision thereby serves as light house defining the direction for future action, without explicitly defining the desired to-be model for a defined date. Using the vision as basis, possible fields of action are identified and prioritised. On an operational level, requirements for the identified courses of action are defined. This is typically conducted on the domain level, as not the entire EA is subjected to change within the identified planning scope. To-be models are created to meet the identified requirements. Also, the time frame for planned changes is determined. Models for a given future time may be created in different variants, e.g., representing different stakeholder priorities. These variants have to be evaluated according to the requirements defined. The evaluation regards budget plans and architectural principles, such as technology standards and design manifestos. The to-be models created on the domain level are consolidated on the enterprise level to create a consistent blueprint for the entire EA for a given future date. This consolidated to-be model is evaluated against the vision defined on the enterprise level. If the defined blueprint suits to operationalise the defined goals, the implementation phase is initiated. Therefore, change projects are defined. On a project level, projects to implement concrete requirements are launched. Projects are monitored, using means of project controlling and quality gates. The process is depicted in Figure 4.

Figure 4 EA planning on enterprise, domains and projects levels

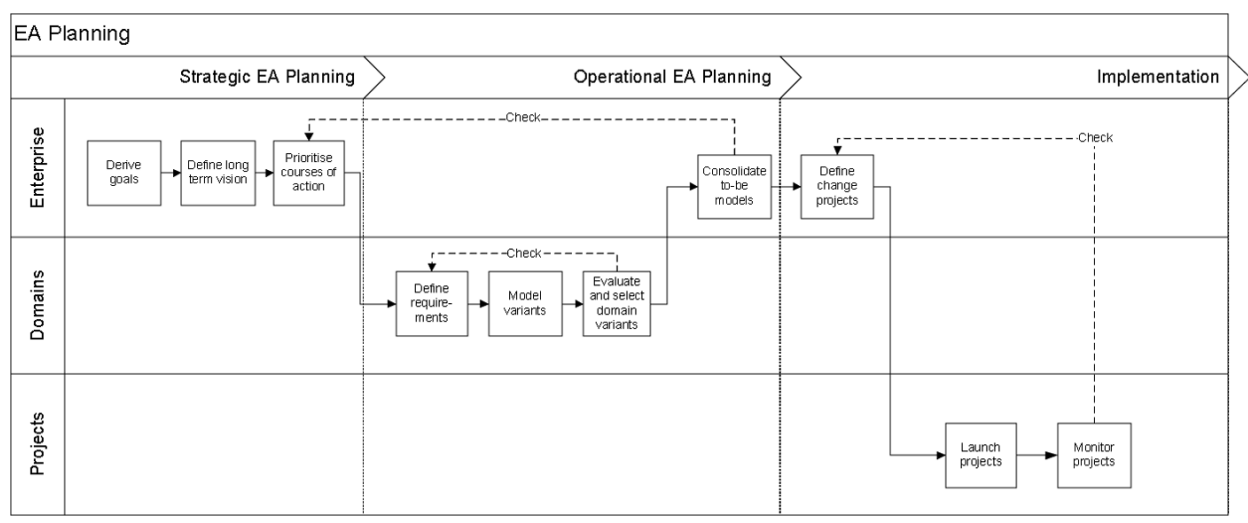

As described earlier, each activity consumes and produces information, typically available in documents, while outputs might be used as inputs in subsequent activities.

Figure 5 gives an overview on documents involved within the planning process. Key documents within EA planning are the architectural models. The process regards as-is models and to-be models. The as-is model is used as input to plan and implement 
changes, whereas the to-be model is used as concrete basis for implementation. Consequently, a distinction between modelling time and realisation time is necessary. The as-is model in time t0 (EA as-is model (old) in Figure 5) is the basis for planning the to-be model in $\mathrm{t} 1$ (EA to-be model), when reaching $\mathrm{t} 1$, the former to-be model serves as as-is model (EA as-is model (new)) when starting subsequent iterations of the planning process, e.g., planning the architecture for $\mathrm{t} 2$.

Figure 5 Documents in EA planning

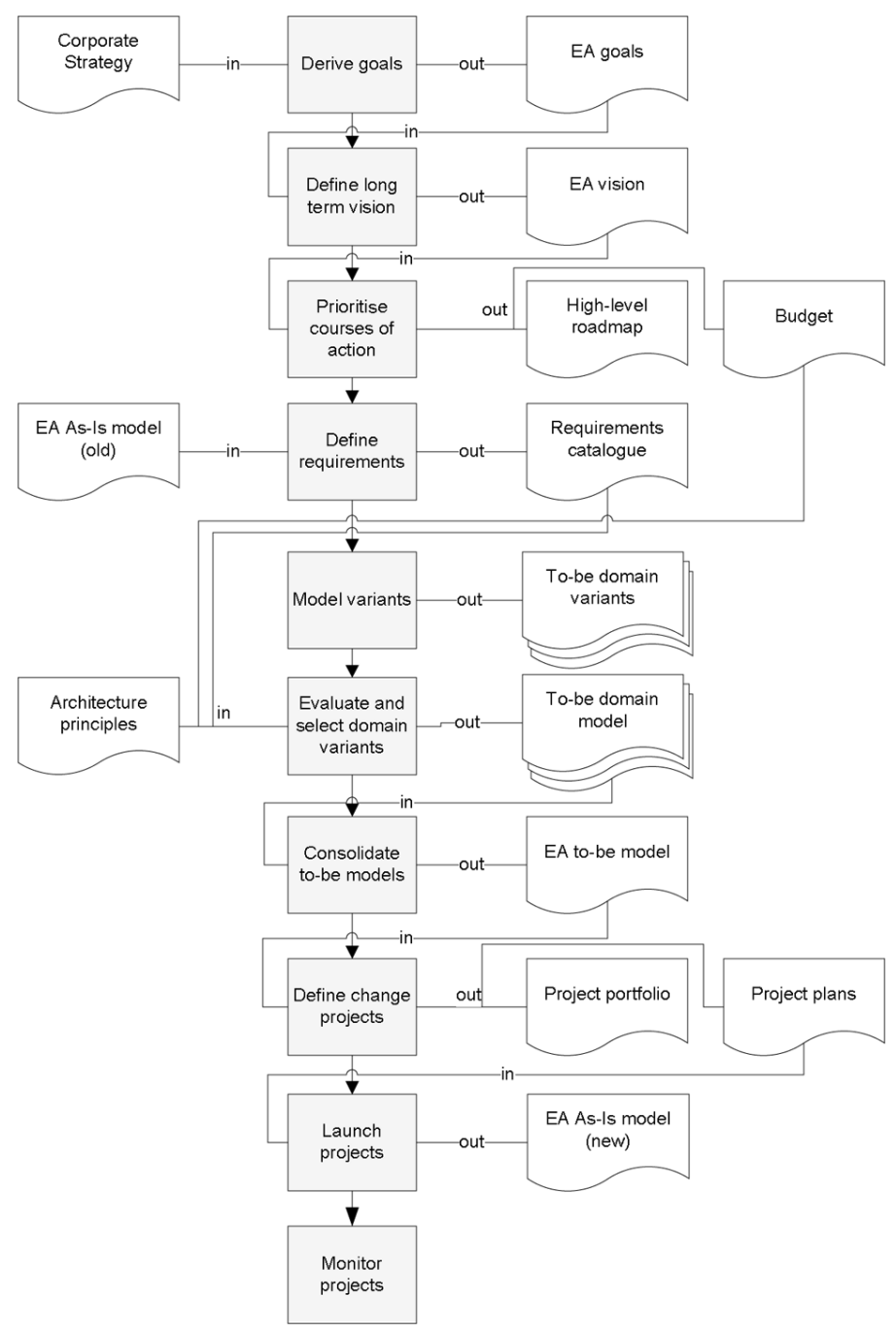

Documents in strategic EA planning define the direction of change. Therefore, EA goals cover business- and IT-related goals, as well as alignment of both worlds. Examples include 'increase time-to-market', 'increase IT maintainability', or 'achieve IT/business alignment'. Accordingly, the EA vision depicts the ideal state of the EA on a high level and neglecting restricting parameters. Therefore, the EA vision defines the rough direction but does need refinement to guide systematic transformation. While fields of 
action are prioritised, high-level roadmaps and a budget plan are resulting. These documents define the general parameters and conditions. As different variants of possible to-be models are created, the evaluation and selection of the most desirable solution is determining the implementation projects. Evaluation and selection is supported by reflecting the requirements catalogue, the budget plan and architectural principles. The to-be domain models are consolidated to become the EA to-be model, which serves as concrete blueprint for transformation and the basis for launching implementation projects.

\section{Results}

To further discuss the differences among the observed EA planning processes (research question 2) and to allocate the observed processes to EA realisation approaches (research question 3), the contingency factors described earlier (cf. Section 3) namely

- $\quad$ adoption of advanced architectural design paradigms and modelling capabilities

- deployment and monitoring of EA data and services

- organisational penetration of EA

are deployed to explicitly explain and address these differences. Thereby, three clusters of EA realisation approaches, namely EA Engineers, EA Initiators and IT Architects, are used to allocate differences within the different EA planning processes within the case studies. Therefore, the characteristics of the realisation approaches are mapped to the activities companies use for EA planning and the situations elicited in the case studies.

EA Engineers are characterised by a high level of organisational penetration and the use of advanced design paradigms and modelling capabilities. Table 2 allocates the case studies fulfilling these characteristics.

Table 2 Allocation of EA engineers

\begin{tabular}{|c|c|c|c|c|c|c|c|c|c|c|}
\hline \multicolumn{11}{|c|}{ Activities in EA planning } \\
\hline & 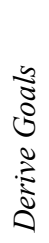 & 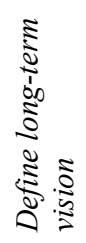 & 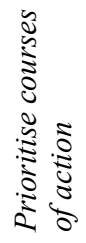 & 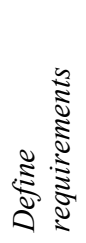 & 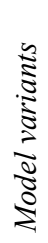 & 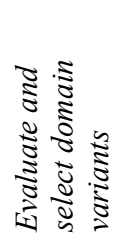 & 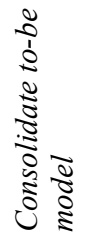 & $\begin{array}{l}0 \\
0 \\
5 \\
0 \\
0 \\
0 \\
0 \\
0 \\
0 \\
0 \\
0 \\
0 \\
0 \\
0\end{array}$ & 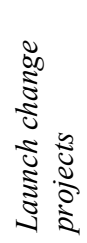 & 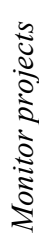 \\
\hline Case study 2 & $\mathrm{X}$ & $X$ & $\mathrm{X}$ & $X$ & $X$ & $\mathrm{X}$ & $\mathrm{X}$ & $X$ & $\mathrm{X}$ & $\mathrm{X}$ \\
\hline Case study 5 & & $X$ & $\mathrm{X}$ & $X$ & $X$ & $\mathrm{X}$ & $\mathrm{X}$ & $X$ & $\mathrm{X}$ & $\mathrm{X}$ \\
\hline Case study 6 & & $\mathrm{X}$ & & $X$ & $\mathrm{X}$ & $\mathrm{X}$ & & $X$ & $X$ & \\
\hline
\end{tabular}

Companies using an explicit and extensive planning process depend not only on sophisticated modelling mechanisms but also on comprehensive governance in place to enable federated planning within domains as multiple roles across the organisation are involved. Governance instruments include EA planning guidelines for federated to-be modelling (e.g., in case study 6) consistency checks on enterprise level to ensure the 
most favourable architecture for the entire company rather than creating local optima (e.g., case studies 2 and 5). Modelling conventions appear to be essential in federated planning of complex transformations, such as depicted in case studies 2 and 5 . The volatility of the business model (transformation of markets in telecommunication and utility industries) demands for close interaction of business and IT, and therefore high degree of organisational penetration.

Table 3 allocates the EA Initiators among the case study partners. This realisation form understands EA as fundamental structure of both business and IT artefacts. The holistic scope can be read from the interconnection with the corporate strategy (Activity 'Derive Goals').

Table 3 Allocation of EA initiators

\begin{tabular}{|c|c|c|c|c|c|c|c|c|c|c|}
\hline \multicolumn{11}{|c|}{ Activities in EA planning } \\
\hline & $\begin{array}{c}\frac{2}{0} \\
0 \\
0 \\
0 \\
\vdots \\
0 \\
0\end{array}$ & 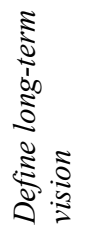 & $\begin{array}{ll} & 5 \\
& 0 \\
0 \\
0 \\
0 \\
0 & 0 \\
\vdots & 0 \\
0 & 0 \\
0 & 0 \\
0 & 0 \\
0 & 0 \\
0 & 0\end{array}$ & 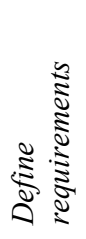 & 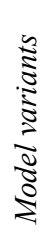 & 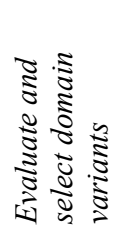 & 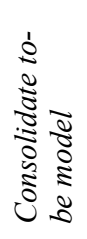 & $\begin{array}{l}\infty \\
\infty \\
\vdots \\
0 \\
0 \\
0 \\
\vdots \\
\vdots \\
0 \\
0 \\
0 \\
0 \\
0\end{array}$ & $\begin{array}{c}0 \\
0 \\
0 \\
0 \\
0 \\
0 \\
0 \\
0 \\
0 \\
0 \\
0 \\
0 \\
0 \\
0 \\
0 \\
0\end{array}$ & 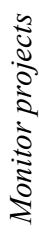 \\
\hline Case study 1 & $\mathrm{X}$ & $\mathrm{X}$ & & $\mathrm{X}$ & & & $\mathrm{X}$ & $\mathrm{X}$ & $\mathrm{X}$ & $\mathrm{X}$ \\
\hline Case study 4 & $X$ & $X$ & & $X$ & & & & $X$ & $X$ & $\mathrm{X}$ \\
\hline
\end{tabular}

EA initiators understand EA planning as centralised task as planning is mainly conducted on enterprise level does not involve domain architects as extensively as EA Engineers. At the same time, as both companies are very large organisations with multitudes of EA stakeholders (e.g., business units, architectural boards, application owners), the consequences of EA planning are wide and affected roles must be included in the process. This represents high organisational penetration. As planning responsibilities are centralised, the demand for advanced modelling capabilities is comparably low. Both companies (case studies 1 and 4) pursue pragmatic modelling approaches to ensure cost-efficient planning.

Case study 3 can be allocated within the cluster IT Architects. As there is no visible connection to the business side and a central planning approach is deployed, the degree of organisational penetration can be considered to be low (Table 4).

Table 4 Allocation of IT architects

\begin{tabular}{|c|c|c|c|c|c|c|c|c|c|c|}
\hline \multicolumn{11}{|c|}{ Activities in EA planning } \\
\hline & $\begin{array}{l}\tilde{\Xi} \\
0 \\
\infty \\
0 \\
\vdots \\
\vdots \\
0 \\
0\end{array}$ & 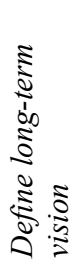 & 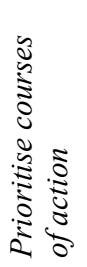 & 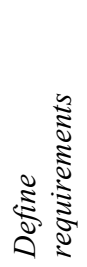 & 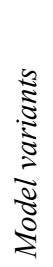 & 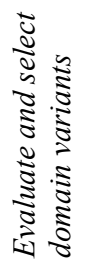 & 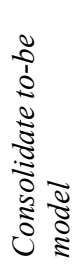 & 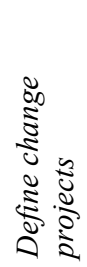 & 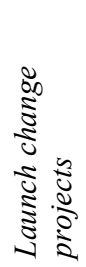 & 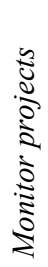 \\
\hline Case study 3 & & $\mathrm{X}$ & & $\mathrm{X}$ & & & & $\mathrm{X}$ & $\mathrm{X}$ & \\
\hline
\end{tabular}


The planning process itself is implicitly defined, yet neither documented nor standardised in case study 3 . The presented planning process is focused exclusively on IT artefacts. A limited number of organisational roles are involved. Given this situation, there is a low demand for sophisticated modelling approaches and design paradigms.

\section{Discussion}

To discuss the differences between analytically derived EA planning processes and the industry-validated EA planning process (research question 1), some characteristics from related work are reflected.

First, the approaches put diverging emphasis on the management of complexity caused by dynamics. As Aier et al. (2009) emphasise feedback loops and unplanned shifts during planning and transformation caused by unforeseen changes within the transition, industry cases verify a more pragmatic solution. Therefore, feedback loops to preceding activities are used to verify to-be models against defined courses of action and to ensure that the to-be model on the domain level meet the requirements. Adjustments to to-be models or transformation plans were, therefore, not mentioned within the case studies. The following reasons might contribute to this difference:

- Maturity of available EA planning methods: As architects mention the demand for sophisticated management of complexity of dynamics, the existing methods lack capabilities supporting these requirements. The need for dynamic adjustments was strongly mentioned by companies facilitating a rather volatile business model.

- Maturity of available EA tools: Subsequently, available software tools lack sophisticated support in the management of complexity of dynamics (Buckl et al., 2008; Matthes et al., 2008). According to analysts, most vendors plan to add functionality to future releases addressing planning capabilities and especially temporality issues (James, 2008; Ganesh and Thompson, 2009; Peyret, 2009). Within the analysed sample, 4 out of 6 companies use dedicated software tools to support EA management. Two companies use standard office tools.

- Modelling efficiency: To understand and manage the complexity of temporal dependencies, additional model data needs to be gathered and maintained. Some architects are uncertain whether the benefits of this information exceed the added efforts and therefore opt for rather pragmatic approaches.

A second difference can be found within the federation of planning levels. The process proposed by Aier et al. (2009) does not distinguish between planning on enterprise, domain, and project level and also the differentiation of strategic planning, operational planning, and implementation plays an important role in industry cases. Centralised planning becomes inefficient for large companies with complex structures. As different characteristic patterns of structure and change can be found at different scales, there are different planning levels with recurring structures and methods, e.g., when planning the entire EA, an architectural layer or parts of it (e.g., application landscape), or a single architectural element (e.g., application) or parts of it (e.g., components) (Saat et al., 2009). The same applies if planning tasks are decentralised as described earlier. Therefore, this difference causes less impact on the execution of planning processes. 
The planning process by Spewak and Hill (1993) and Spewak and Tiemann (2006) emphasises the order of blueprinting data architecture, application architecture, and then technology architecture. This could not be observed in case studies. In practice, the planning scope is broader as data, applications and technologies are only parts of the EA. Spewak does not relate to any business-related artefacts, such as, e.g., business processes.

The approach by Pulkkinen and Hirvonen (2005) and Pulkkinen (2006) uses the hierarchical federation of enterprise, domain and systems. Similar observations can be made in practice - although with another purpose for EA planning. As Pulkkinen and Hirvonen (2005) and Pulkkinen (2006) emphasise a reuse of successful concepts in domains and systems on the enterprise level, practitioners use the hierarchical federation to ensure consistent planning. Therefore, plans are driven by a common vision and to-be models for domains are consolidated on an enterprise level as basis for the management for implementation projects.

\section{Summary and outlook}

This paper analyses processes for EA planning. The contribution contains three parts relating to research questions $1-3$ posed in the introduction.

1 On the basis of six case studies, a comprehensive EA planning process is compiled.

Analytically derived EA planning processes from literature are compared with the case-study-based planning processes used in practice.

2 As the case studies deliver different selections of activities within the processes the companies use, different configurations of the EA planning process are identified.

3 On the basis of the previous work, the different configurations of the planning process are assorted to EA realisation forms.

The proposed process extends the existing approaches by the feasibility verified by industry professionals. Resulting from our study, there is a gap between the desired and the realised degree in sophistication of EA planning. Companies seeking to formalise and institutionalise their EA planning process can use the proposed planning process and tailor it according to their realisation form of EA management. Further gaps in this field exist in the management of dynamic aspects within EA planning. Current and future research activities are conducted by the authors in the field of modelling transformation itself. It is thereby investigated, how metamodels can be designed to support certain transformation goals. Related research efforts focus on the capturing of dynamics in EA models. In this context, we are currently developing an approach to model life cycles of EA models and respective elements as well as versioning and precursor and successor relationships.

Because of the diverse understanding and approaches to EA management, scientific approaches should focus on the development of artefacts that can be tailored according to situational needs. To do so, further insights on contingency factors describing these situations (e.g., detailed information on project types and contexts of situations) are needed. As this contribution focuses on a procedure model for such a method, next steps should address techniques to provide recommendations of how to perform the proposed activities. 


\section{References}

Aier, S. and Winter, R. (2009) 'Virtual decoupling for IT/Business alignment - conceptual foundations, architecture design and implementation example', Business and Information Systems Engineering, Vol. 51, pp.150-163.

Aier, S., Buckl, S., Franke, U., Gleichauf, B., Johnson, P., Närman, P., Schweda, C.M. and Ullberg, J. (2009) 'A survival analysis of application life spans based on enterprise architecture models', Proceedings of 3rd International Workshop on Enterprise Modelling and Information Systems Architectures, Ulm, pp.141-154.

Aier, S., Riege, C. and Winter, R. (2008) 'Classification of enterprise architecture scenarios - an exploratory analysis', Enterprise Modelling and Information Systems Architectures, Vol. 3, pp.14-23.

Albani, A., Barjis, J. and Dietz, J.L.G. (Eds.) (2009) 'Advances in Enterprise Engineering III', 5th International Workshop, CIAO! 2009, and 5th International Workshop, EOMAS 2009, held at CAiSE 2009, 8-9 June, Amsterdam, The Netherlands, Springer, Berlin, Heidelberg.

Alter, S. (2003) ' 18 reasons why IT-reliant work systems should replace 'The IT Artifact' as the core subject matter of the IS field', Communications of the Association for Information Systems, Vol. 12, pp.366-395.

Alter, S. (2006) 'Work systems and IT artifacts - Does the definition matter?', Communications of the Association for Information Systems, Vol. 17, pp.299-313.

Bernus, P., Nemes, L. and Schmidt, G. (Eds.) (2003) Handbook on Enterprise Architecture, International Handbooks on Information Systems, Springer, Berlin, Heidelberg, New York.

Brinkkemper, S. (1996) 'Method engineering: engineering of information systems development methods and tools', Information and Software Technology, Vol. 38, pp.275-280.

Bucher, T., Klesse, M., Kurpjuweit, S. and Winter, R. (2007) 'Situational method engineering - on the differentiation of 'context' and 'project type', in Ralyté, J., Brinkkemper, S. and Henderson-Sellers, B. (Eds.): Proceedings of IFIP WG8.1 Working Conference on Situational Method Engineering - Fundamentals and Experiences (ME07), Geneva, pp.33-48.

Buckl, S., Dierl, T., Matthes, F., Ramacher, R. and Schweda, C.M. (2008) 'Current and future tool support for EA management', in Steffens, U., Addicks, J.S. and Streekmann, N. (Eds.): Proceedings of Workshop MDD, SOA und IT-Management (MSI 2008), Oldenburg, pp.9-24.

Buckl, S., Ernst, A.M., Matthes, F. and Schweda, C.M. (2009a) 'An information model for managed application landscape evolution', Journal of Enterprise Architecture, Vol. 5, pp.12-26.

Buckl, S., Ernst, A.M., Matthes, F. and Schweda, C.M. (2009b) 'Visual roadmaps for enterprise architecture evolution', Proceedings of International Workshop on Enterprise Architecture Challenges and Responses (WEACR 2009), Daegu, South Korea.

Dietz, J.L.G. (2006) Enterprise Ontology - Theory and Methodology, Springer, Berlin, Heidelberg.

Fischer, R., Aier, S. and Winter, R. (2007) 'A federated approach to enterprise architecture model maintenance', Enterprise Modelling and Information Systems Architectures, Vol. 2, pp.14-22.

Fox, M.S. and Gruninger, M. (1998) 'Enterprise modeling', AI Magazine, Vol. 19, pp.109-121.

Frank, U. (2002) 'Perspective enterprise modeling (MEMO) - conceptual framework and modeling languages', Proceedings of 35th Hawaii International Conference on System Sciences (HICSS-35), Big Island, HI.

Ganesh, B. and Thompson, M. (2009) Strategic IT Planning and Control Suite - v8, Butler Group Technology Audit TA001547ITM.

Gutzwiller, T.A. (1994) Das CC RIM-Referenzmodell für den Entwurf von betrieblichen, transaktionsorientierten Informationssystemen, Physica, Heidelberg. 
Harmsen, A.F., Brinkkemper, S. and Oei, H. (1994) 'Situational method engineering for information system project approaches', in Verrijn-Stuart, A.A. and Olle, T.W. (Eds.): Proceedings of Proceedings of the IFIP 8.1 Working Conference on Methods and Associated Tools for the Information Systems Life Cycle, Amsterdam, pp.169-194.

Hirvonen, A. and Pulkkinen, M. (2004) 'A practical approach to EA planning and development: the EA management grid', in Abramowicz, W. (Ed.): Proceedings of 7th International Conference on Business Information Systems (BIS 2004), Poznan, pp.284-302.

Hoogervorst, J.A.P. (2009) Enterprise Governance and Enterprise Engineering, Springer, Berlin.

James, G.A. (2008) Magic Quadrant for Enterprise Architecture Tools, Gartner Research G00156427.

Johnson, P. and Ekstedt, M. (2007) Enterprise Architecture: Models and Analyses for Information Systems Decision Making, Studentlitteratur, Pozkal.

Jonkers, H., Lankhorst, M., van Buuren, R., Hoppenbrouwers, S., Bonsangue, M. and van der Torre, L. (2004) 'Concepts for modelling enterprise architectures', International Journal of Cooperative Information Systems, Vol. 13, pp.257-287.

Jonkers, H., Lankhorst, M.M., Doest, H.W.L., Arbab, F., Bosma, H. and Wieringa, R.J. (2006) 'Enterprise architecture: management tool and blueprint for the organisation', Information Systems Frontiers, Vol. 8, pp.63-66.

Katz, R.L. (1990) 'Business/enterprise modeling', IBM Systems Journal, Vol. 29, pp.509-525.

Kirikova, M. (2000) 'Explanatory capability of enterprise models', Data and Knowledge Engineering, Vol. 33, pp.119-136.

Kosanke, K., Vernadat, F. and Zelm, M. (1999) 'CIMOSA: enterprise engineering and integration', Computers In Industry, Vol. 40, pp.83-97.

Kumar, K. and Welke, R.J. (1992) 'Methodology engineering - a proposal for situation-specific methodology construction', in Cotterman, W. and Senn, J.A. (Eds.): Challenges and Strategies for Research in Systems Development, John Wiley \& Sons, New York, pp.257-269.

Kurpjuweit, S. and Winter, R. (2009) 'Concern-oriented business architecture engineering', Proceedings of 24th Annual ACM Symposium on Applied Computing (SAC 2009), Honolulu, HI.

Lankhorst, M. (2005) Enterprise Architecture at Work: Modelling, Communication and Analysis, Springer, Berlin, Germany.

Leppänen, M., Valtonen, K. and Pulkkinen, M. (2007) 'Towards a contingency framework for engineering an enterprise architecture planning method', Proceedings of 30th Information Systems Research Seminar in Scandinavia (IRIS 2007), Tampere, Finland.

Liles, D.H. and Presley, A.R. (1996) 'Enterprise modeling within an enterprise engineering framework', Proceedings of 28th Conference on Winter Simulation, New York, NY, pp.993-999.

Luftman, J.N. (2000) 'Assessing business-IT alignment maturity', Communications of the Association for Information Systems (AIS), Vol. 4, pp.1-50.

Matthes, F., Buckl, S., Leitel, J. and Schweda, C.M. (2008) Enterprise Architecture Management Tool Survey 2008, Software Engineering for Business Information Systems (SEBIS) Ernst Denert-Stiftungslehrstuhl Chair for Informatics 19 TU München, München.

Niemann, K.D. (2006) From Enterprise Architecture to IT Governance, Elements of Effective IT Management, Vieweg, Wiesbaden.

Niemi, E. (2007) 'Enterprise architecture stakeholders - a holistic view', Proceedings of 13th Americas Conference on Information Systems (AMCIS 2007), Keystone.

Op't Land, M., Proper, E., Waage, M., Cloo, J. and Steghuis, C. (2009) Enterprise Architecture Creating Value by Informed Governance, Springer, Berlin. 
Peyret, H. (2009) Forrester Wave: Business Process Analysis, EA Tools, And IT Planning, Q1 2009, Forrester Research, Cambridge, MA, USA.

Pulkkinen, M. (2006) 'Systemic management of architectural decisions in enterprise architecture planning. Four dimensions and three abstraction levels', in Sprague Jr., R.H. (Ed.): Proceedings of 39th Hawaii International Conference on System Sciences (HICSS-39), Honolulu, HI.

Pulkkinen, M. and Hirvonen, A. (2005) 'EA planning, development and management process for agile enterprise development', in Sprague Jr., R.H. (Ed.): Proceedings of 38th Hawaii International Conference on Systems Sciences (HICSS-38), Big Island, HI.

Riege, C. and Aier, S. (2009) 'A contingency approach to enterprise architecture method engineering', in Feuerlicht, G. and Lamersdorf, W. (Eds.): Proceedings of Service-Oriented Computing - ICSOC 2008 Workshops, Sydney, pp.388-399.

Rohloff, M. (2008) 'Framework and reference for architecture design', Proceedings of 14th Americas Conference on Information Systems (AMCIS 2008), Toronto.

Saat, J., Aier, S. and Gleichauf, B. (2009) 'Assessing the complexity of dynamics in enterprise architecture planning - lessons from Chaos Theory', Proceedings of 15th Americas Conference on Information Systems (AMCIS 2009), San Francisco.

Schelp, J. and Winter, R. (2009) 'Language communities in enterprise architecture research', in Vaishanvi, V. and Baskerville, R. (Eds.): Proceedings of 4th Conference on Design Science Research in Information Systems and Technologies (DESRIST 2009), Philadelphia, PA, pp.1-10.

Schönherr, M. (2009) 'Towards a common terminology in the discipline of enterprise architecture', in Feuerlicht, G. and Lamersdorf, W. (Eds.): Proceedings of Service-Oriented Computing ICSOC 2008 Workshops, Sydney, pp.400-413.

Shaw, M. (1990) 'Prospects for an engineering discipline of software', IEEE Software, Vol. 7, pp.15-24.

Sousa, P., Lima, J., Sampaio, A. and Pereira, C. (2009) 'An approach for creating and managing enterprise blueprints: a case for IT blueprints', in Albani, A., Barijs, J. and Dietz, J.L.G. (Eds.): Proceedings of 5th International Workshop on Cooperation \& Interoperability Architecture \& Ontology (CIAO! 2009) in Conjunction with the CaiSE'09 Conference, Amsterdam, pp.70-84.

Spewak, S.H. and Hill, S.C. (1993) Enterprise Architecture Planning - Developing a Blueprint for Data, Applications and Technology, John Wiley \& Sons, New York.

Spewak, S.H. and Tiemann, M. (2006) 'Updating the enterprise architecture planning model', Journal of Enterprise Architecture, Vol. 2, pp.11-19.

The Open Group (2009) The Open Group: TOGAF Version 9 - The Open Group Architecture Framework (TOGAF), Van Haren, Zaltbommel.

Theuerkorn, F. (2004) Lightweight Enterprise Architectures, Auerbach, Boca Raton.

Tyler, D.F. and Cathcart, T.P. (2006) 'A structured method for developing agile enterprise architectures', in Verma, A.K. (Ed.): Proceedings of International Conference on Agile Manufacturing (ICAM 2006), Norfolk, Virginia, pp.1-8.

van Slooten, K. and Hodes, B. (1996) 'Characterizing IS development projects', in Brinkkemper, S., Lytinnen, K. and Welke, R.J. (Eds.): Proceedings of IFIP TC8, WG8.1/8.2 Working Conference on Method Engineering, Berlin, pp.29-44.

Vernadat, F. (1996) Enterprise Modeling and Integration - Principles and Applications, Chapman \& Hall, London.

Wegmann, A. (2002) The Systemic Enterprise Architecture Methodology (SEAM) - Business and IT Alignment for Competiveness, École Poytechnique Fédérale de Lausanne, Lausanne.

Winter, R. and Fischer, R. (2007) 'Essential layers, artifacts, and dependencies of enterprise architecture', Journal of Enterprise Architecture, Vol. 3, pp.7-18. 
Winter, R., Bucher, T., Fischer, R. and Kurpjuweit, S. (2007) 'Analysis and application scenarios of enterprise architecture - an exploratory study', Journal of Enterprise Architecture, Vol. 3, pp.33-43.

Yin, R.K. (2003) Case Study Research. Design and Methods, 3rd ed., Sage Publications, Thousand Oaks, CA, USA.

Ylimäki, T. (2006) 'Potential critical success factors for enterprise architecture', Journal of Enterprise Architecture, Vol. 2, pp.29-40.

Zachman, J.A. (1987) 'A framework for information systems architecture', IBM Systems Journal, Vol. 26, pp.276-292. 